\title{
A novel marker to determine arrhytmia risk in elite cyclists: $\mathrm{T}$ peak $\mathrm{T}$ end
}

\section{Bulent ISIK ${ }^{1}$, Z. Isik SOLAK GORMUS², Huseyin ASLAN ${ }^{3}$, Abdullah ICLI ${ }^{4}$, Galip Bilen Kurklu' ${ }^{5}$, Ozgur CIFTCI ${ }^{6}$, Turhan TOGAN ${ }^{7}$}

${ }^{1}$ Departments of Ambulance Service, Provincial Health Directorate, Konya, Turkey.

${ }^{2}$ Departments of Physiology and ${ }^{4}$ Cardiology, ${ }^{5}$ Sports Medicine, Meram Medical School, University of Necmettin Erbakan, Konya, Turkey.

${ }^{3}$ Faculty of Sport Science, Selçuk University, Konya, Turkey.

${ }^{6}$ Departments of Cardiology, Private Akademi Hospital, İmit, Turkey.

${ }^{7}$ Departments of Infectious Diseases, Private Can Hospital, Manisa, Turkey.

Address correspondence to B. Isik, e-mail: drbulent42@gmail.com

\begin{abstract}
In athletes, left ventricular hypertrophy is a physiological response upon routine active sports. If the hypertrophic cardiomyopathy is not diagnosed and treated, it can lead to sudden deaths in athletes. Not so much data is known whether or not it is favorable to use of Tp-e values in order to reflect the arrhythmia risks in asymptomatic elite cyclists. The aim of this study is to examine the risks of regular bike sport on potential arrhythmia in healthy active elite cyclists and veterans by using non-invasive cardiac tests. Study groups were: healthy volunteers (group 1, $\mathrm{n}=28$, mean age $35.8 \pm 4.6$ ), active cyclists (group 2, $\mathrm{n}=27$, mean age 21 \pm 3.0 ), veteran cyclists (group 3, $\mathrm{n}=27$, mean age 29.5 $\pm 7.1 \mathrm{yr}$ ). All groups were underwent cardiological examinations, 12 derivation ECG records, transthoracic echocardiography investigations. Tp-e interval, Tp-e dispersion, corrected Tp-e interval, QT interval and Tp-e/QT ratio were calculated from ECG records. Tp-e intervals were measured with Tangent method, corrected Tp-e interval were measured with Bazett formula. Mean Tp-e interval results were as follows according to groups $1,2,3 ; 75.0 \pm 9.3,88.1 \pm 7.0,83.2 \pm 8.8 \mathrm{~ms}$, respectively. The Tp-e interval, cTp-e interval, Tp- dispersion, QT interval, and SLI values were significantly higher in active cyclists than the veteran cyclists and the control group $(\mathrm{p}<0.05)$. Both cyclist groups had also significantly higher Tp-e interval, cTp-e interval, QT interval, Tp-e/QT, QRS time and SLI values than the control group $(\mathrm{p}<0.05)$. Furthermore, there were significant differences in Tp-e interval, cTp-e interval, Tp-e dispersion, QT interval and SLI values between the active and veteran cyclists $(\mathrm{p}<0.05)$. There were significant differences in Tp-e dispersion between active cyclists and control group or veteran cyclists $(\mathrm{p}<0.01)$. Arrythmia related to Tp-e interval, Tp-e dispersion, corrected Tp-e interval and Tp-e/QT ratio are associated with long-term, intense bike sport training either in active cyclists or veterans. This can also be associated with left ventricular hypertrophy in active cyclists and remnant left ventricular hpertrophy in veterans.
\end{abstract}

Keywords: Arrhythmia, electrocardiographic predictor, elite cyclists, t peak- t end interval.

\section{INTRODUCTION}

Regularly conducted intensive training can lead to cardiac hypertrophy known as athlete's heart (16). Electrocardiographic reflections on cardiac structural and electrical restructuring due to regular training are common in athletes (29). Cardiac electrical changes closely related to the increase in left ventricular mass developing in compliance with training are also widely observed in veteran athletes without cardiovascular disease (32). Changes in the athlete's heart must not be considered a purely innocent, physiological phenomenon, with no possible negative consequences $(24,32)$. For instance; pathologic left ventricular hypertrophy
$(\mathrm{LVH})$ and repolarization abnormality signs are observed more commonly in athlete's electrocardiography (ECG) (19). There is also an increase at the risk of developing supraventricular arrhythmias in veteran athletes. Possible causes of this increasing arrhythmia risk in veteran athletes include increased parasympathetic modulation during rest and increased atrial diameter with increased sympathetic modulation during exercise, and autonomic changes involving increased inflammation (34).

There can be a possible unconfirmed structural heart disease in a healthy athlete who does not have any cardiovascular symptom. Indeed, athletes with 
pathological ECG findings should be followed very well (19). Left ventricular hypertrophy is a clinical status which is associated with sudden cardiac death and all cardiovascular mortalities (20). There is an important relationship between the pathological left verntricular hypertrophy and the deterioration in ECG parameters including signs of ventricular repolarization homogeneity (33).

Ventricular repolarization parameters have not yet been studied comparatively in healthy and asymptomatic elite active and veteran cyclists. It has still been discussed whether or not the hypertrophic changes due to regular training in athletes lead to arrhythmia or death. Depending on cardiac hypertrophy, it is considered that arrhythmia may occur as a result of the elongation of the action potential time in myocardial cells and; therefore, the increment in the ventricular repolarization time (11).

The Tp-e interval [time from the peak to the end of the $\mathrm{T}$ wave (Tp-e)] which reflects the transmural distribution of repolarization in ECG and Tp-e dispersion and Tp-e / QT ratio which are the other transmiocardial repolarization parameters are closely related parameters with increased risk of cardiac arrhythmia (3-27).

The purpose of this study is to examine the potential pathological repolarization changes and possible arrhythmia risks which may develop due to the regular bike sport training in asymptomatic elite cyclists.

\section{MATERIALS \& METHODS}

\section{Study population}

In this prospective study, there were 27 active (24 male, 3 female) and 27 veteran (27 male) elite cyclists and 28 healthy volunteers (15 male, 13 female) between the ages of 18-45. Total number of participants were 88 . The medical histories of the participants were taken and their physical examinations were carried out. Their ECG and echocardiography (ECO) were taken and basal blood tests were performed. Groups of the study were; Group 1: Control group, group 2: Active cyclists; and group 3: Veteran cylists. This study was conducted in line with the ethical principles of the Declaration of Helsinki and the recommended guidelines. Before starting the study, written informed consent was obtained from each participant and the Ethics Committee of Necmettin Erbakan University Clinical Investigations approved the study protocol. (Date/Approval number: 2014/104).

The active cyclists who participated in this study have been performing bike sport training almost every day for the last 5 years. The majority of these cyclists have participated in both national and international competitions and they've had many success. Veteran cyclists were elite and winning cyclists who had performed a similar level of sports before and who have not participated in competitions for the last 1 year. While active cyclists reported that they have performed regular bicycle training and competitions for 5-12 years, veteran cyclists reported 5-15 years.

Exclusion criteria included the presence of a valvular heart disease, anemia hypertrophic cardiomyopathy (HCMP) disease, coronary artery abnormalities or congenital heart disease, aortic stenosis, cardiomyopathy, heart failure, and atrial fibrillation, frequent atrial or ventricular extrasystoles which were monitored in ECG. All participants had the sinus rhythm and they were not receiving any medical treatment during the study.

\section{Physical Examination and Laboratory Tests}

The cardiological examinations of participants were performed after 12-hour hunger. Some parameters such as height $(\mathrm{Ht})$, weight $(\mathrm{Wt})$, body mass index (BMI), body surface area (BSA), heart rate and blood pressure were measured with the physical examination. BMI and BSA were calculated as it is indicated in the formula below upon obtaining the findings of $\mathrm{Ht}$ and $\mathrm{Wt}$ :

$$
\begin{gathered}
\mathrm{BMI}=\mathrm{Wt}(\mathrm{kg}) / \mathrm{Ht}^{2}(\mathrm{~m}) \text { and BSA }=0: 007184 \times \mathrm{Wt}^{0.425} \mathrm{x} \\
\mathrm{Ht}^{0.725}(28) .
\end{gathered}
$$

Venous blood samples were collected from each participant in order to assess serum blood lipid levels (total cholesterol, high, low and very lowdensity lipoproteins, trigliseride), glucose, BUN, creatinin, sodium and potassium, high sensitiveCRP and hematology blood tests (hemoglobin, hematocrit, trombocyte).

\section{Electrocardiographic Measurements}

ECG records were taken at a velocity of $25 \mathrm{~mm}$ $\mathrm{s}^{-1}$ and amplitude of $10 \mathrm{~mm} \mathrm{mV}^{-1}$ during rest in the supine position using a 12-lead ECG. The Philips Andover MA 01810 USA device was used in order to perform ECG measurements. The rested heart rates of participants were calculated by using digital ECG technique. In order for evaluations to be 
optimal and error-free, a computer with 600-dpi resolution was used to screen the ECG results. The results were assessed by two cardiologists who were not informed about each other and the status of participants. Tp-e and corrected Tp-e (cTp-e) intervals were calculated with the help of the computer program by using a manual ruler measuring instrument in order to obtain highly sensitive measurements (17) (Fig. 1).

QT interval was calculated from the beginning of the QRS complex which reflects to Q, R and S waves till the end of the $T$ waves in all derivations of ECG, and averages were recorded for each group. In this study, the Tangent Method was used in order to measure $\mathrm{T}$ peak-T end in precordial leads and mean values were calculated for each group (10).

The point of intersection $\mathrm{T}$ wave line descending with tangent line and the isoelectric line was defined as the end of the $\mathrm{T}$ wave. (When $\mathrm{T}$ wave is not followed by an $U$ wave or if it is not distinct from the following $U$ wave). If the $T$ wave was negative or biphasic, the tangent line was drawn by marking the lowest point. When the $\mathrm{T}$ wave was followed by $U$ wave, the deepest point between $\mathrm{T}$ and $U$ waves was accepted as the end of the $T$ wave. The Tp-e interval was calculated by measuring the distance between two points on the isoelectric line. When the $\mathrm{T}$ wave amplitude was less than $1,5 \mathrm{~mm}$, that derivation measurement was excluded from the study (1-17). The differences among the max and min Tp-e values in precordial derivations were defined as Tp-e dispersion. The Tp-e intervals were corrected with the Bazett formula $[\mathrm{cTp}-\mathrm{e}=\mathrm{Tp}-\mathrm{e} / \sqrt{ }(\mathrm{RR}$ interval)] according to the heart rate (1-35). Tp-e/QT ratio was calculated by using Tp-e and QT interval values. Variabilities of inter-and intraobservers were found in Tp-e as 5,1\% and 3,8\%, respectively.

QRS intervals were calculated from the beginning of the $Q$ wave till the end of $S$ wave in all derivations and averages were recorded for each group (Its point of return in the isoelectric line). However, in the absence of the $Q$ wave, the beginning of the $\mathrm{R}$ wave was accepted as the measurement start point of the QRS wave (2).

In order to perform the electrocardiographic assessment of the $\mathrm{LVH}$, classical Sokolow-Lyon criteria was used (S-wave amplitude in lead $\mathrm{V}_{1}+\max$ R-wave amplitude in lead $\mathrm{V}_{5}$ or $\mathrm{V}_{6}$ ) (15).

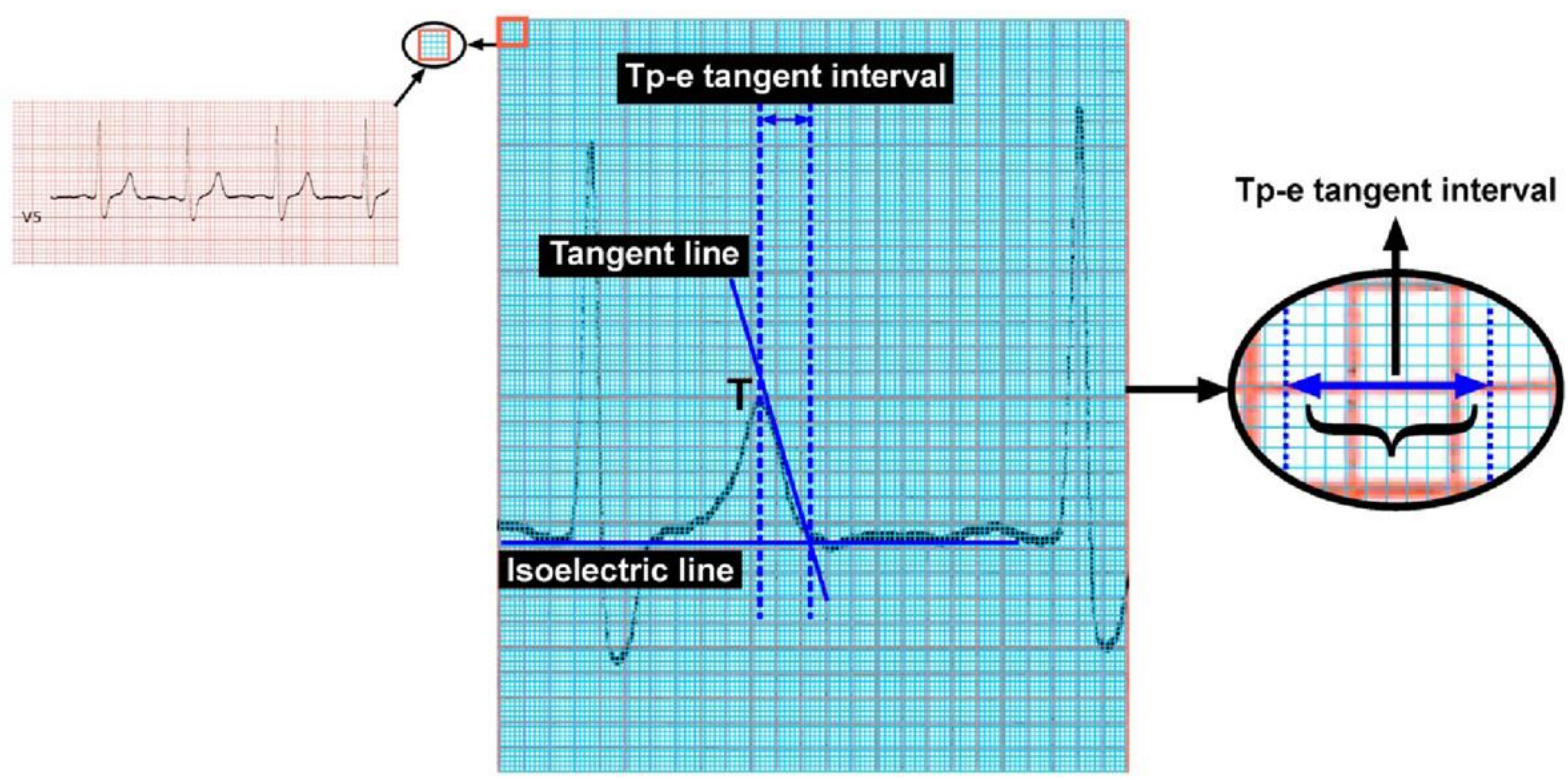

Figure 1. Tp-e measurement with the help of the Tangent Method by using a computer program.

\section{Echocardiographic Measurements}

The echocardiographic records were obtained with the help of an instrument called Acuson Sequoia C256R Echocardiography System equipped with a 3V2c broadband transducer with second harmonic capability (Acuson Corp, Mountain View,
Calif, USA).The participants were examined in the lateral decubitus position by using two-dimensional, M-mode, and subsequent standard and pulsed tissue Doppler echocardiography. Echocardiographic images were recorded on VHS video tapes. These parameters measured by using 
parasternal long-axis views of the participants were diastolic and systolic interventricular septal thickness (IVST), left ventricular posterior wall thickness (LVPWT), and left ventricular end diastolic (LVEDd) and left ventricular end-systolic (LVEDs) diameters.The measurements were performed by M-mode imaging obtained from 2-D guides.

\section{Left ventricular mass determination}

M-Mode records were taken on parasternal long-axis images for the calculations of left ventricular mass (LVM). The left ventricular mass was calculated using the formula proposed by Devereux (7). The left ventricular mass indexes (LVMI) were considered as LVM per meter squared of body surface area. It was indicated that men had the excessive left ventricular hypertrophy (LVMI) value as equal to or greater than $125 \mathrm{~g} / \mathrm{m}^{2}$ whereas this value was determined as $110 \mathrm{~g} / \mathrm{m}^{2}$ for women (22).

\section{Statistical analysis}

Statistical analyses were performed with the help of SPSS 15.0 program (SPSS for Windows 15.0; SPSS Inc., Chicago, Illinois, USA). Values related to the quality variables were expressed as number (n) and continuous variable values were expressed as mean \pm standard deviation (SD). Levine test was used in the variance analyses of groups. In the statistical evaluation of the parametric (categorical) data, one way analysis of variance (ANOVA) was used. In order to analyze the non-parametric (noncategorical) data, we used Mann-Whitney U test. P values which were less than 0.05 were accepted as statistically significant. In order to determine the correlations between parameters, Pearson correlation test was used when the distribution was normal (parametric) and Sperman correlation test was used when the distribution was not normal (non-parametric).

\section{RESULTS}

A total of 82 participants were classified into three groups. As it can be seen in Table 1, the demographic and clinical features of each participant were obtained. The average ages of the participants were calculated in group 1 (control group), 2 (active cyclists) and 3 (veteran cyclists) as $35.8 \pm 4.6,21.0 \pm 3.0$, and $29.5 \pm 7.1 \mathrm{yr}$, respectively. There were totally 16 females (19.5\%) and 66 males $(80.5 \%)$ in the current study. There were no significant differences in sex, degree in sport competition or $\mathrm{Ht}$ between active and veteran cyclist groups $(p>0.05)$. The active cyclists were significantly younger than the other groups $(p<0.01)$.

ISC: International sport competition, SBP: Systolic blood pressure (mm Hg), DBP: Diastolic blood pressure $(\mathrm{mm} \mathrm{Hg}), \mathrm{Wt}$ : weight $(\mathrm{kg}), \mathrm{Ht}$ : Height $(\mathrm{cm})$, BMI: Body mass index $\left(\mathrm{kg} / \mathrm{m}^{2}\right)$, BSA: Body surface area $\left(\mathrm{m}^{2}\right)$, IVSTd: Inter ventricular septum thickness during diastole $(\mathrm{cm})$, LVMI: Left ventricular mass index $\left(\mathrm{gr} / \mathrm{m}^{2}\right), \mathrm{n}$; number. The results are given as $\mathrm{n}(\%)$ or mean \pm standard deviations. A $\mathrm{p}$ value $<0.05$ was accepted as statistically significant $\left(^{*}\right)$.

Table 1. Comparison of the clinical and demographic characteristics among the groups.

\begin{tabular}{|c|c|c|c|c|c|c|c|c|}
\hline \multicolumn{2}{|c|}{ Variables } & $\begin{array}{c}\text { Group 1 } \\
\text { Control Group } \\
(\mathrm{n}=28)\end{array}$ & $\begin{array}{c}\text { Group } 2 \\
\text { Active Cyclists } \\
(\mathrm{n}=27)\end{array}$ & $\begin{array}{c}\text { Group } 3 \\
\text { Veteran Cyclists } \\
(\mathrm{n}=27)\end{array}$ & $\begin{array}{c}\mathrm{p} \\
\text { Value } \\
(1-2)\end{array}$ & $\begin{array}{c}\mathrm{p} \\
\text { Value } \\
(1-3)\end{array}$ & $\begin{array}{c}\mathrm{p} \\
\text { Value } \\
(2-3)\end{array}$ & $\begin{array}{c}\mathrm{p} \\
\text { Value } \\
\text { General }\end{array}$ \\
\hline \multirow{3}{*}{$\begin{array}{l}\text { Age (year) } \\
\text { Sex, n }(\%)\end{array}$} & & $35.8 \pm 4.6$ & $21.0 \pm 3.0$ & $29.5 \pm 7.1$ & $<0.001^{*}$ & $<0.001^{*}$ & $<0.001^{*}$ & $<0.001^{*}$ \\
\hline & Male & $15(53.6)$ & $24(88.9)$ & $27(100)$ & $0.004^{*}$ & $<0.001^{*}$ & 0.246 & $<0.001^{*}$ \\
\hline & Female & $13(46.4)$ & $3(11.1)$ & 0 & $<0.001^{*}$ & $<0.001^{*}$ & 0.246 & $<0.001^{*}$ \\
\hline \multicolumn{2}{|l|}{ ISC, n (\%) } & 0 & $23(85.2)$ & $27(100)$ & $<0.001^{*}$ & $<0.001^{*}$ & $0.039^{*}$ & \\
\hline \multicolumn{2}{|c|}{ Degree in SC, n (\%) } & 0 & $27(100)$ & $27(100)$ & $<0.001^{*}$ & $<0.001^{*}$ & 1.000 & \\
\hline \multicolumn{2}{|c|}{ SBP (mmHg) } & $112.8 \pm 5.3$ & $107.2 \pm 6.8$ & $108.8 \pm 8.5$ & $0.004^{*}$ & $0.038^{*}$ & 0.383 & $0.011^{*}$ \\
\hline \multicolumn{2}{|c|}{ DBP (mmHg) } & $72.1 \pm 6.1$ & $66.6 \pm 7.7$ & $71.1 \pm 8.9$ & $0.010^{*}$ & 0.619 & $0.036^{*}$ & $0.024^{*}$ \\
\hline \multicolumn{2}{|l|}{ Wt (kg) } & $77.3 \pm 15.5$ & $65.5 \pm 6.9$ & $79.1 \pm 8.2$ & $0.002^{*}$ & 0.535 & $<0.001^{*}$ & $<0.001^{*}$ \\
\hline \multicolumn{2}{|l|}{$\mathrm{Ht}(\mathrm{cm})$} & $168 \pm 8.1$ & $174.7 \pm 6.4$ & $178.2 \pm 6.0$ & $0.001^{*}$ & $<0.001^{*}$ & 0.064 & $<0.001^{*}$ \\
\hline \multicolumn{2}{|c|}{ BMI $\left(\mathrm{kg} / \mathrm{m}^{2}\right)$} & $27.3 \pm 4.9$ & $21.4 \pm 1.4$ & $24.9 \pm 2.6$ & $<0.001^{*}$ & $0.01^{*}$ & $<0.001^{*}$ & $<0.001^{*}$ \\
\hline \multicolumn{2}{|l|}{$\mathrm{BSA}\left(\mathrm{m}^{2}\right)$} & $1.86 \pm 0.19$ & $1.79 \pm 0.12$ & $1.97 \pm 0.11$ & 0.077 & $0.018^{*}$ & $<0.001^{*}$ & $<0.001^{*}$ \\
\hline \multirow{2}{*}{\multicolumn{2}{|c|}{$\begin{array}{l}\text { IVSTd }(\mathrm{cm}) \\
\text { LVMI }\left(\mathrm{gr} / \mathrm{m}^{2}\right)\end{array}$}} & $0.95 \pm 0.18$ & $1.02 \pm 0.16$ & $0.99 \pm 0.14$ & 0.126 & 0.409 & 0.480 & 0.097 \\
\hline & & $104.8 \pm 20.9$ & $111.5 \pm 30.2$ & $126.9 \pm 26.5$ & 0.345 & $0.002^{*}$ & $0.034^{*}$ & 0.117 \\
\hline
\end{tabular}


Table 2. The comparison of electrocardiographic results between groups.

\begin{tabular}{|c|c|c|c|c|c|c|c|}
\hline Variables & $\begin{array}{l}\text { Group } 1 \\
\text { Control } \\
\text { Group } \\
(n=28)\end{array}$ & $\begin{array}{l}\text { Group } 2 \\
\text { Active } \\
\text { Cyclists } \\
(\mathrm{n}=27)\end{array}$ & $\begin{array}{l}\text { Group 3- } \\
\text { Veteran } \\
\text { Cyclists } \\
(\mathrm{n}=27)\end{array}$ & $\begin{array}{c}\mathrm{p} \\
\text { Value } \\
(1-2)\end{array}$ & $\begin{array}{c}\mathrm{p} \\
\text { Value } \\
(1-3)\end{array}$ & $\begin{array}{c}\mathrm{p} \\
\text { Value } \\
(2-3)\end{array}$ & $\begin{array}{c}\mathrm{p} \\
\text { Value } \\
\text { General }\end{array}$ \\
\hline HR (beat/m) & $75.7 \pm 9.5$ & $55.4 \pm 10$ & $59.9 \pm 8.4$ & $<0.001^{*}$ & $<0.001^{*}$ & 0.085 & $<0.001^{*}$ \\
\hline Tp-e interval (ms) & $75.0 \pm 9.3$ & $88.1 \pm 7.0$ & $83.2 \pm 8.8$ & $<0.001^{*}$ & $0.001^{*}$ & $0.035^{*}$ & $<0.001^{*}$ \\
\hline cTp-e interval (ms) & $67.3 \pm 10.7$ & $92.8 \pm 11.3$ & $84.1 \pm 12.2$ & $<0.001^{*}$ & $<0.001^{*}$ & $0.007^{*}$ & $<0.001^{*}$ \\
\hline Tp-e Dispersion (ms) & $21.9 \pm 7.9$ & $36.7 \pm 19.4$ & $23.1 \pm 12.8$ & $0.001^{*}$ & 0.753 & $0.001^{*}$ & $<0.001^{*}$ \\
\hline QT interval (ms) & $341.2 \pm 16.5$ & $379.1 \pm 22.3$ & $357.1 \pm 23.1$ & $<0.001^{*}$ & $0.006^{*}$ & $<0.001^{*}$ & $<0.001^{*}$ \\
\hline Tp-e/QT & $0.21 \pm 0.02$ & $0.22 \pm 0.02$ & $0.22 \pm 0.02$ & $0.044^{*}$ & $0.044^{*}$ & 1.000 & 0.066 \\
\hline QRS time (ms) & $85.3 \pm 10.6$ & $91.7 \pm 8.9$ & $95.2 \pm 13.7$ & $0.039^{*}$ & $0.002^{*}$ & 0.266 & $0.006^{*}$ \\
\hline SLI (RV5+SV1) (mV) & $1.49 \pm 0.44$ & $3.22 \pm 1.04$ & $2.37 \pm 0.72$ & $<0.001^{*}$ & $<0.001^{*}$ & $0.004^{*}$ & $<0.001^{*}$ \\
\hline
\end{tabular}

HR: Heart rate at resting (beat/m), cTp-e interval: Corrected Tp-e interval (ms), SLI: Sokolow-Lyon index (mV), The results are given as mean \pm standard deviations. A p value $<0.05$ was accepted as statistically significant $\left(^{*}\right)$.

Furthermore, the active cyclist group had significantly lower $\mathrm{Wt}$ and $\mathrm{BMI}$ values compared to other groups $(p<0.01)$. There were no significant differences in BSA between active cyclists and control group $(p>0.05)$. The SBP values were significantly higher in control groups compared to the other cyclist groups $(\mathrm{p}<0.05)$. Beside, there were no significant differences in SBP between both of cyclist groups ( $p>0.05)$. DBP was also significantly higher in control group than the active cyclists $(p<0.01)$. Also, there was no significant difference in DBP among control group and veteran cyclists $(\mathrm{p}>0.05)$.

According to the comparison between groups in terms of their echocardiographic data, there was no difference in case of IVSTd ( $p>0.05)$. As it can be seen in Table 1, veteran cyclists had significantly higher LVMI values compared to control group and active cyclists $(\mathrm{p}<0.05)$.

The electrocardiographic findings of participants were listed in Table 2. The control group had significantly higher HR values compared to the cyclist groups $(p<0.01)$. There were no significantly differences in HR values between both of cyclist groups $(\mathrm{p}>0.05)$.

As it is shown in Table 2, both cyclists groups had also significantly higher Tp-e interval, cTp-e interval, QT interval, Tp-e/QT, QRS time and SLI values than the control group $(\mathrm{p}<0.05)$. Furthermore, there were significant differences in Tp-e interval, cTp-e interval, Tp- dispersion, QT interval and SLI values between active cyclists and veteran cyclists $(\mathrm{p}<0.05)$. The Tp-e/QT values were equal in cyclists and there were no significant differences in mean Tp-e/QT ratio between cyclist groups $(p>0.05)$. On the other hand, there was a significant difference in Tp-e dispersion between active cyclists and control group or veteran cyclists $(\mathrm{p}<0.01)$. The Tp-e interval, cTp-e interval, Tp-e dispersion, QT interval, and SLI values were significantly higher in active cyclists than the veteran cyclists and control groups $(\mathrm{p}<0.05)$.

There was a positive correlation between the Tp-e interval and IVSTd in active cyclists ( $p ; 0.039$, r; 0.845 ). Additionally, there was a positive correlation between an increased IVSTd $(0.99 \pm 0.14 \mathrm{~cm})$ which is a sign for $\mathrm{LVH}$ and the cTp-e interval in veteran cyclists ( $p ; 0.002, r ; 0.993$ ). There was also a positive correlation between Tp-e/QT ratio and increased LVM $(247.0 \pm 61.3 \mathrm{gr})$ as well as LVMI $(126.9 \pm 26.5$ $\left.\mathrm{gr} / \mathrm{m}^{2}\right)$ in veteran cyclists ( $\mathrm{p} ; 0.026, \mathrm{r} ; 0.896, \mathrm{p} ; 0.031$, r; 0.877 respectively). Similarly, the Tp-e/QT ratio and BMI $\left(21.4 \pm 1.4 \mathrm{~kg} / \mathrm{m}^{2}\right)$ values of active cyclists were also positively correlated to each other ( $p$; $0.040, \mathrm{r} ; 0.842$ ).

In current study, the Sokolow-Lyon Index $\left(\mathrm{RV}_{5}+\mathrm{SV}_{1}\right)$ criteries were calculated in order to determine the electrocardiographic diagnosis of $\mathrm{LVH}$. As it can be noticed from the findings, the active cyclists had the highest SLI values. There were significantly differences in SLI values between active cyclists and veteran cyclists or control group $(p<0.01)$. There were also significant differences in SLI values between veteran cyclists and control group $(p<0.01)$. Furthermore, there was a positive 
correlation between the SLI and LVEDd values of veteran cyclists ( $p ; 0.024, r ; 0.907)$.

\section{DISCUSSION}

In current study, some significant cardiac morphological and electrical changes which include an increase in LVMI and a prolongation of ventricular repolarization parameters and if there is an effect of these changes on the risk of potential arrhythmia were examined in asymptomatic active and veteran elite cyclists by using electrocardiography and echocardiography.

The present study demonstrates that the LVMI values which are indicators of $\mathrm{LVH}$ in echocardiography were significantly higher in veteran cyclists than in both the healthy control subjects and active cyclists $(p<0.05)$, while there is no significant difference between the control groups and active cyclists ( $p>0.05)$.

\section{On}

the other hand, the results of this study reveals that the ventricular repolarization parameters such as Tp-e interval, cTp-e interval, QT interval and Tpe/QT ratio values, which are assoiciated with an increased risk of cardiac arrthmia were significantly prolonged in both cyclists compared to control groups $(p<0.05)$. The current study shows that the Tp-e interval, cTp-e interval, Tp- dispersion, QT interval and SLI values were significantly higher in active cyclists than the veteran cyclists or control groups, too $(\mathrm{p}<0.05)$.

Many structural alterations including increased left ventricular mass observed in the athletic heart, is a different clinical case which is a variant of normal due to continuous training, These alterations may vary according to the type of sport and the severity of training $(8,36)$.

In present study, the reason for the significant increase of LVMI in veteran cyclists compared to other groups was that veteran cyclists had a longer competitive training history according to active cyclists. The mean periods of the competitive trainings were 7.0 and 9.7 years in active and veterans cyclists, respectively. Furthermore, increased LVMI levels in veteran cyclists are especially associated with persistent cardiac hypertrophic effects of regular endurance sports in veterans or remnant cardiac hypertrophy (32).

Increased isolated voltage criteria of left ventricular hypertrophy (increased $R$ or $S$ wave voltage) and repolarization abnormalities were more often observed in elite athletes including cyclists (30). The appearance of both repolarization disorders and isolated voltage criteria of left ventricular hypertrophy indicates pathological left ventricular hypertrophy in athletes. These abnormalities can also refer to structural heart diseases, which can lead to rhythm disorder (19). Some novel datas have demonstrated an increased prevalence of ventricular arrhythmias in endurancetrained active athletes and particularly in veterans (26). Many recent studies which promote the potential pathological alterations in the cardiac electrical mobility have stated a partial reversal of left ventricular hypertrophy in veteran elite athletes as a process of pathological remodelling (4). It is because there are increments in the electrical wave amplitudes due to hypertrophy in the ventricle of a hypertrophic heart. This study demonstrates that the SLI values which are voltage criteria of LVH in electrocardiography were significantly higher in both the cyclists than in control subjects $(p<0.01)$ and that the SLI values positively correlated with the LVEDd values of veteran cyclists. Morever, in this study, the SLI values were found to be $44 \%$ in active cyclists (>3.5 mV, hypertrophic). Whereas, Hong et al. showed that the SLI values were $65 \%$ in cyclists and $20 \%$ in football players (15). In this study population, the active cyclists had significantly the highest SLI values $(3.22 \pm 1.04 \mathrm{mV})$. All of these findings suggest that the electrical and mass effects of cardiac hypertrophy may take a lifetime in cyclists.

The situation developing as a result of cardiac compliance during sport training in athletes is in favor of physiological LVH. On the other hand, the systemic hypertension and the aortic stenosis in which there is chronic pressure overload (12) and HCMP which is one of the chronic myocardial diseases are in favor of pathological LVH. The differentiation of the pathological and physiological LVH is extremely important since the most common reason for sudden deaths in athletes is undiagnosed HCMP (23). Echocardiography is a standard diagnostic tool which is used in order to differentiate the pathological and physiological LVH. In pathological cardiac hypertrophies, on a cellular level, myocardial fibers grow, cellular metabolism and cardiac structure change, myocardial dysfunction occurs, ultimately mortality and morbidity increase (9-25). In pathological hypertrophy, electrophysiological properties of 
cardiomyocytes change and high susceptibility to malignant tachyiarrhythmias occurs. Furthermore, the ventricular repolarization is also deteoriated in a hypertrophic heart with fibrosis (25).

If there is no other reason, lifelong, intensive, endurance training may result in fibrous replacement of the ventricular myocardium. This may be beginning of a pathological process for the spread of arrhythmias. (37).

The regular, intense endurance sport training leads to an increment in a cardiac myocyte length and capacitance (11). Physiological hypertrophy is characterized by the lack of interstitial collagen growth or minimal interstitial collagen growth and myocyte hypertrophy with regular reflection (21). Following cardiac hypertrophy, prolongation of APD is observed in mid-myocardial and subepicardial myocytes. However, prolongation of action potential duration (APD) is referred as the principal electrical response to hypertrophy for the bulk of the myocytes making up the left ventricular mass. So, the different variations in channel expression highlight the regional effects of hypertrophy in APD (11). In these regions, the repolarization phases change which lead, then, to transmyocardial heterogeneity and consequently to malignant arrhythmias. The transmyocardial heterogeneity is determined through the calculation of Tp-e interval, Tp-e dispersion, and Tp-e/QT ratio, via an ECG (18).

Hence, the Tp-e interval has been perceived as an index of transmural dispersion of repolarization (TDR). The ratio of TDR to the total duration of repolarization (expressed as Tp-e/QT ratio) has been employed as an ECG index of ventricular arrhythmogenesis. Compared to the total duration of the repolarization, a disproportionate increase (Tp-e/QT ratio) in the transmural distribution of repolarization has the proarrhythmic effect. The fact that Tp-e/QT ratio is in the normal limitations plays an important role in the electrical stability of myocardium stability. Tp-e/QT ratio is 0.21 in normal individuals in precordial derivations (10). In the current study, the Tp-e/QT ratios in both cyclists were $0.22 \pm 0.02 \mathrm{~ms}$ and it was significantly prolonged compared to previous ratio. It has been observed significant differences between both cyclists groups and control groups $(\mathrm{p}<0.05)$.

If the Tp-e interval is prolonged, this may lead to an increase in vulnerable arrhythmia caused by ventricular reentry (1). The increase in TDR has been observed in participants who have hypertension, obesity and in animal models of ventricular hypertrophy (31-38) In the current study, TDR (Tp-e interval) was shown to be significantly higher in young, healthy, elite active and veteran cyclists than in control subjects $(\mathrm{p}<0.01)$. Moreover, active cyclists had significantly highest Tp-e dispersion value, which is a sign of the variation in transmyocardial repolarization across regions of the myocardium $(\mathrm{p}<0.01)$. Similarly, Hevia et al. have suggested that the dispersion of Tp-e in ECG is a beneficial parameter that can be used for risk layering in cases with Brugada Syndrome (13).

Alizade et al. found that Tp-e interval and Tpe/QT ratio increased in athletes with a pathological $\mathrm{LVH}$ and they also showed that there was a positive correlation between the LVMI and these two electrophysiological values. However, Braschi et al. showed that there was no significant increase in ventricular repolarization parameters in active athletes with physiological LVH and Hong et al. similarly stated that there was no significant increase in Tp-e interval in active athletes (5). These two studies were performed only with active athletes in order to show the short term effects of sports on repolarization behaviors. In our study, we examined the long term effects of bike sport in veteran cyclists in addition to the short term effects of bike sport on repolarization behaviors in active cyclists.

As a result, it was found that parameters of ventricular repolarization were prolonged in both cyclist groups. Therefore, we can conclude that the prolongation of the parameters of ventricular repolarization due to the regular and intensive bike training is not temporary in elite cyclists and this prolongation also continues after leaving the bike sport. Thus, it is considered that the prolonged repolarization parameters due to bike sport in both cyclist groups can lead to increase of the arrhythmia risk in any period of their life.

The significant decrease in HR in cyclist groups compared to control group $(p<0.01)$ is due to the dominant parasympathetic influence during resting period as a result of training $(5,6)$.

According to the results of this study, we showed that ventricular arrhythmia and sudden death related mean Tp-e interval, cTp-e interval, QT interval and Tp-e/QT ratio values are significantly 
prolonged in asymptomatic active and veteran elite cyclists compared to control groups. Furthermore, we concluded that physiologic LVH due to the long term bike training activity was significantly and positively associated with electrocardiographic findings such as cTp-e interval and Tp-e/QT ratio in veteran cyclists. Very few data is known whether or not it is favorable to use of Tp-e values in order to reflect the arrhythmia risks in young, healthy, asymptomatic elite cyclists. Our findings suggest that prolonged Tp-e values can be used to be a sign of a cardiovascular disease and a predictor of arrhythmia in cyclists who do not have any cardiovascular complaints and findings.

Study Limitations: This study was performed with a limited number of sporters from limited type of sports only during the resting period. Cyclists could not be observed in terms of long term arrhythmia. Similar studies can be performed with the participation of a wider group of athletes from different varieties of sports. In further studies, the ECG recordings can be obtained during the exercise, resting and recovery periods. In the future studies, higher number of participants can be observed for a long time in order to determine long term effects of regular and intensive sport training.

In conclusion; long-term, intensive bike sport trainings in asymptomatic and healthy cyclists can lead to prolonged Tp-e interval, Tp-e dispersion, corrected Tp-e interval and Tp-e/QT ratio values which are are associated with potential arrythmia. This can be related to left ventricular hypertrophy in individuals who are actively doing bike sports and remnant left ventricular hypertrophy in veterans. Regular intensive cycling training can lead to repolarization abnormalities in heart and this abnormality can be lifelong. As a conclusion, these repolarization abnormalities due to the bike training in cyclists can be easily determined by using an applicable, cheap and non-invasive test which is called ECG.

\section{ACKNOWLEDGEMENT}

This study was supported by Necmettin Erbakan University Scientific Research Project Coordinator. Researchers declared no conflict of interest or financial support.

\section{REFERENCES}

1. Akıllı NB, Akıncı E, Akıllı H, Dündar ZD, Köylü R, Polat M, Cander B. A new marker for myocardial injury in carbonmonoxide poisoning: $\mathrm{T}$ peak-T end. American Journal of Emergency Medicine, 2013; 31: 1651-1655.

2. Alizade E, Avcı, A, Fidan S, Tabakçı M, Bulut M, Zehir R, Akçakoyun $\mathrm{M}$. The effect of chronic anabolic-androgenic steroid use on Tp-E interval, Tp-E/Qt ratio, and Tp-E/Qtc ratio in male bodybuilders. Annals of Noninvasive Electrocardiology, 2015; 20(6): 592-600.

3. Antzelevitch C. Tpeak-Tend interval as an index of transmural dispersion of repolarization. European journal of clinical investigation, 2001; 31(7): 555-557.

4. Baldesberger S, Bauersfeld U, Candinas R Seifert B, Zuber M, Ritter M, Jenni R, Oechslin E, Luthi P, Scharf C, Marti B, Attenhofer Jost $\mathrm{CH}$. Sinus node disease and arrhythmias in the long-term follow-up of former professional cyclists. Eur Heart J, 2008; 29 (1): 71-78.

5. Braschi A, Francavilla VC, Abrignani MG, Todaro L, Francavilla G. Behavior of repolarization variables during exercise test in the athlete's heart. Annals of Noninvasive Electrocardiology, 2012; 17(2): 95-100.

6. Buchheit M, Gindre C. Cardiac parasympathetic regulation: Respective associations with cardiorespiratory fitness and training load. Am J Physiol Heart Circ Physiol, 2006; 291(1): 451-458.

7. Devereux RB, Reichek N. Echocardiographic determination of left ventricular mass in man. Anatomic validation of the method. Circulation, 1977; 55: 613-618.

8. Fagard R. Athlete's heart. Heart, 2003; 89(12): 1455-1461.

9. Florescu M, Vinereanu D. How to differentiate athletes heart from pathological cardiac hypertrophy? Mædica A Journal of Clinical Medicine, 2006; 1: 19-26.

10. Gupta P, Patel C, Patel H, Narayanaswamy S, Malhotra B, Green JT, Yan GX. Tp-e/QT ratio as an index of arrhythmogenesis. Journal of Electrocardiology, 2008; (41): 567-574.

11. Hart G. Exercise induced hypertrophy: a substrate for sudden death in athletes? Experimental Physiology, 2003; 88(05): 639644.

12. Heineke J, Molkentin JD. Regulation of cardiac hypertrophy by intracellular signalling pathways. Nature reviews Molecular cell biology, 2006; 7(8): 589-600.

13. Hevia JC, Antzelevitch C, Bárzaga FT, Sánchez MD, Balea FD, Molina RZ, Rodríguez, YF. T peak-T end and T peak-T end dispersion as risk factors for ventricular tachycardia/ventricular fibrillation in patients with the Brugada syndrome. Journal of the American College of Cardiology, 2006; 47(9): 1828-1834.

14. Hlaing T, Guo D, Zhao X, Di Mino T, Greenspon L, Kowey PR, Yan GX. The QT and Tpe intervals in left and right chest leads: comparison between patients with systemic and pulmonary hypertension. Journal of electrocardiology, 2005; 38(4): 154-158.

15. Hong L, Andersen LJ, Graff C, Vedel-Larsen E, Wang F, Struijk JJ, Kanters JK. T-wave morphology analysis of competitive athletes. Journal of electrocardiology, 2015; 48(1): $35-42$.

16. Huston TP, Puffer JG, Mac Millan Rodney WM. The athletic heart syndrome. N Engl J Med, 1985; 313: 24-32. 
17. Icli A, Kayrak M, Akilli H, Aribas A, Coskun M, Ozer SF, Ozdemir K. Prognostic value of Tpeak-Tend interval in patients with acute pulmonary embolism. BMC cardiovascular disorders, 2015; 15(1): 99.

18. Kayrak M, Acar K, Gul EE, Ozbek O, Abdulhalikov T, Sonmez $\mathrm{O}$, Alibaşiç $\mathrm{H}$. The association between myocardial iron load and ventricular repolarization parameters in asymptomatic beta-thalassemia patients. Adv Hematol, 2012; (2012): 170510.

19. Kiss O, Sydó N, Vargha P, Édes E, Merkely G, Sydó T, Merkely B. Prevalence of physiological and pathological electrocardiographic findings in Hungarian athletes. Acta Physiologica Hungarica, 2015; 102(2): 228-237.

20. Kreger BE, Cupples LA, Kannel WB. The electrocardiogram in prediction of sudden death: Framingham Study experience. American Heart Journal, 1987; 113(2): 377-382.

21. Lattanzi F, Di Bello V, Picano E, Caputo MT, Talarico L, Di Muro C, Distante A. Normal ultrasonic myocardial reflectivity in athletes with increased left ventricular mass. A tissue characterization study. Circulation, 1992; 85(5): 18281834.

22. Marcus R, Krause L, Weder AB, Dominguez-Meja A, Schork NJ, Julius S. Sex-specific determinants of increased left ventricular mass in the Tecumseh Blood Pressure Study. Circulation, 1994; 90: 928-936.

23. Maron BJ. Sudden death in young athletes. New England Journal of Medicine, 2003; 349(11): 1064-1075.

24. McCann GP, Muir DF, Hillis WS. Athletic left ventricular hypertrophy: Long-term studies are required. Eur Heart J, 2000; 21: 351-353.

25. McIntyre H, Fry CH. Abnormal action potential conduction in isolated human hypertrophied left ventricular myocardium. Journal of cardiovascular electrophysiology, 1997; 8(8): 887894.

26. Mont L, Elosua R, Brugada J. Endurance sport practice as a risk factor for atrial fibrillation and atrial flutter. Europace, 2009; 11 (1): 11-17.

27. Morin DP, Saad MN, Shams OF, Owen JS, Xue JQ, Abi-Samra FM, Milani RV. Relationships between the T-peak to T-end interval, ventricular tachyarrhythmia, and death in left ventricular systolic dysfunction. Europace, 2012; 14: 11721179 .

28. Omiya K, Sekizuka H, Kida K, Suzuki K, Akashi YJ, Ohba H, Musha $\mathrm{H}$. Influence of gender and types of sports training on
QT variables in young elite athletes. European Journal of Sport Science, 2014; 14(S1): 32-38.

29. Pavlik G, Major Z, Varga-Pinter B, Jeserich M, Kneffel Z: The athlete's heart Part I (Review). Acta Physiol. Hung, 2010; 97: 337-353.

30. Pelliccia A, Di Paolo FM, Quattrini FM, Basso C, Culasso F, Popoli G, De Luca R, Spataro A, Biffi A, Thiene G, Maron BJ. Outcomes in athletes with marked ECG repolarization abnormalities. N Engl J Med, 2008; 358(2): 152-161.

31. Russo V, Ammendola E, De Crescenzo I, Ricciardi D, Capuano P, Topatino A, Docimo L, Santangelo L, Calabrò R. Effect of weight loss following bariatric surgery on myocardial dispersion of repolarization in morbidly obese patients. Obes Surg, 2007; 17(7): 857-86.

32. Sharashidze N, Pagava Z, Saatashvili G, Kishmarcia T, Agladze R. Exercise induced QT Dispersion changes in middle-aged veteran elite athletes. Georgian Med News, 2008; (157): 53-55.

33. Shimizu $M$, Ino $H$, Okeie $K$, Yamaguchi $M$, Nagata $M$, Hayashi K, Mabuchi H. T-peak to T-end interval may be a better predictor of high-risk patients with hypertrophic cardiomyopathy associated with a cardiac troponin I mutation than QT dispersion. Clinical Cardiology, 2002; 25(7): 335-339.

34. Sorokin AV, Araujo CGS, Zweibel A, Thompson PD. Atrial fibrillation in endurance-trained athletes. Br J Sports Med, 2011; 45(3):185-188.

35. Tatlisu MA, Özcan KS, Güngör B, Ekmekçi A, Çekirdekçi EI, Arugarslan E, Erdinler I. Can the T-peak to T-end interval be a predictor of mortality in patients with ST-elevation myocardial infarction? Coronary Artery Disease, 2014; 25(5): 399-404.

36. Thompson PD. D. Bruce Dill. Historical lecture. Historical concepts of the athlete's heart. Medicine and Science in Sports and Exercise, 2004; 36(3): 363-370.

37. Whyte GP, Sheppard M, George KP, Shave RE, Wilson M, Stephens N, Senior R, Sharma S. Arrhythmias and the athlete: mechanisms and clinical significance. Eur Heart J, 2007; 28(11): 1399-1401 author reply 1401.

38. Yan GX, Rials SJ, Wu Y, Liu T, Xu X, Marinchak RA, Kowey PR. Ventricular hypertrophy amplifies transmural repolarization dispersion and induces early after depolarization. Am J Physiol Heart Circ Physiol, 2001; 281(5): 1968- 1975. 